\title{
Justice and the Resource of Time: a Reply to Goodin, Terlazzo, von Platz, Stanczyk, and Lim
}

\author{
JULIE L. ROSE \\ Dartmouth College
}

\section{INTRODUCTION}

The contributors offer a rich collection of constructive and careful arguments. I am grateful for their thoughtful comments which, drawing on their own work and the book, broaden and advance the discussion of free time as a matter of justice in new and fruitful directions. While my response will in part involve clarifying and developing my argument on behalf of citizens' claims to the resource of free time, I have aimed to engage with their arguments in the same productive spirit, tracing potential avenues of future work.

I begin with Robert Goodin's contribution, and the question of how free time ought to be conceptualized for a public and feasible theory of justice, in particular - as Goodin presses - so that it allows for empirical measurement. I turn then to Rosa Terlazzo's argument, which draws our attention to considering the array of social conditions that must obtain to enable citizens to make effective use of their free time, and liberties and opportunities more generally. I next take up Jeppe von Platz's argument, which asks whether the effective freedoms principle can support citizens' claims to a fair share of free time as a matter of cooperative fairness. Continuing the question of fair shares, Lucas Stanczyk asks how a theory of social justice should respond to class disparities in access to free time, developing this question by asking whether harried wealthy professionals ought to be regarded as having (more than) their fair shares of free time. Finally, Désirée Lim's argument considers the temporal dimensions of republicanism, examining the question of how a republican theory of justice might ground an entitlement to free time. 


\section{THE REQUIREMENTS OF A PUBLIC AND FEASIBLE THEORY OF JUSTICE: A RESPONSE TO GOODIN}

My account of the resource of free time both draws on and departs from Goodin et al.'s conception of discretionary time (2008), and similarly my response here will both highlight ways in which our two approaches are and may be more convergent, while also maintaining what I take to be some important points of divergence.

Goodin's central challenge to my conception of free time is how well it meets the requirements of empirical measurement. I share Goodin's view that the operative conception of free time must allow for empirical assessment. To be a resource to which citizens have claims in a public and feasible theory of justice, I argue that it must be possible to reliably and verifiably know whether an individual possesses the resource, and to obtain this information efficiently and noninvasively (Rose 2016: 46-47). Goodin et al.'s conception readily allows for empirical measurement, as their Discretionary Time (2008), an important advance in the study of time, clearly demonstrates. Accordingly, in taking up this challenge, my aim is to show that my conception of free time meets the requirements for assessments that are both feasible and reliable.

On both of our accounts, free or discretionary time is to be distinguished from necessary time - the time that one must spend to meet the necessities of life (Rose 2016: 4, 42; Goodin et al. 2008: 5-6, 34). The differences in our approaches arise in how to conceptualize and assess this time. The approach Goodin et al. take - which I term the social benchmark approach - follows, as Goodin here notes, the standard conceptualization of a relative poverty line (that is, a poverty threshold set relative to a society's median income, rather than an absolute measure of deprivation). Dividing one's total necessary time into the categories of paid labor, unpaid household labor, and personal care, they assess one's necessary time in paid labor as how much time it takes one to earn a poverty-level income at one's wage rate, and one's necessary time in unpaid household labor and in personal care, respectively, as fifty and eighty percent of the median amount of time people in one's society spend in such activities, indexed, in the former, to one's household structure (Goodin et al. 2008: 34-53).

The approach I take - the basic needs approach - instead conceptualizes one's necessary time as how much time it is objectively necessary for one, taking account of relevant circumstances, to spend to meet one's own, and one's dependents', basic needs, which are the demands one standardly must meet in order to attain a basic level of functioning in one's society (Rose 2016: 42 n. 5, 58). 
Justice and the Resource of Time: a Reply to Goodin, Terlazzo, von Platz, Stanczyk, and Lim

Though the philosophical conception of free time underlying the basic needs approach could be fully tailored to a given individual's relevant circumstances (i.e. how much time it is necessary for one, given all one's very particular circumstances, to meet one's basic needs), such a maximally individually tailored approach fails to meet the feasibility requirements of a public theory of justice, as it would not be possible for a public authority to practically make such an assessment efficiently or noninvasively. As such, I argue, the basic needs approach should be only moderately tailored to individual circumstances, such that it more generally assesses how much time it takes people in a set of relevant circumstances to meet their basic needs (Rose 2016: 46-47, 57).

The basic needs approach differs from the social benchmark approach in two key respects: First, on the social benchmark approach, as operationalized by Goodin et al., the assessment of necessary time is tailored only to wage rate and household structure, while the basic needs approach is tailored to any individual circumstances that a theory of justice or democratic decision renders relevant (Rose 2016: 60-65). Second, while the social benchmark approach assesses necessary time purely relatively, the basic needs approach has both absolute and relative components (following Sen 1983). ${ }^{1}$

The first distinction is not a deep one, as the social benchmark approach could be operationalized in a more fine-grained way, as Goodin notes, if there were a suitable data set (Goodin 2017: 41). Indeed, this is a potential point of greater convergence, as my approach indicates that more comprehensive circumstance-tailored time-use data must be collected in order to empirically operationalize the basic needs conception of free time.

Goodin argues that though the two approaches could converge in this way, the added granularity would come at a cost, because public policy does and should operate through a system of general rules, and ought not to be unduly driven by the need to accommodate the very special circumstances of some small subgroup (Goodin 2017: 41). This point about generality is well taken, but I don't think it obviates the need for more finegrained data for sound public policymaking. Consider, for instance, the question of where to invest in improving the speed and efficiency of a city's public transportation systems. It might be the case that the city's highincome workers, who choose to live in its suburbs, and its low-income

1 On whether necessary time should be measured by a relative or absolute standard, see the exchange between Goodin et al. (2011) and Bittman (2011); see also Williams, Masuda, and Tallis (2016). For a measure that relies on an absolute standard, see Hobbes et al. (2011). 
workers, who can afford to live only in its outer rings, spend the same amount of time commuting into work, but the low-income workers spend more necessary time commuting - a distinction that could be made only with more fine-grained data, and that ought to inform a just transportation policy. Further, when there are exceptional cases that ought to be treated separately from general social policy, even on a case-by-case basis, the basic needs approach provides the required conceptual grounds for such assessments.

The second distinction is more significant. Consider the question of how much time it is necessary to spend grocery shopping, cooking, and eating. The social benchmark approach determines how much time it is necessary to spend on these tasks as half the median amount of time people in one's society in fact spend on these tasks, tailored to some set of circumstances. On the basic needs approach, these relative comparisons are relevant - how much time people around you spend in necessary activities does provide meaningful guidance about what is socially necessary to function in one's society - but they are not determinative. Say that the median amount of time that full-time employed parents spend grocery shopping, cooking, and eating is only five hours per week. The assessment of necessary time might reflect that, but it could also be adjusted by democratic or expert judgment about how much time it is objectively necessary to spend in these tasks. Consistent with its underlying conceptualization, the basic needs approach allows for such adjustments in instances in which people generally might, due to competitive pressures or social norms, spend either more or less time than is objectively necessary to meet a basic need (Rose 2016: 55).

Beyond these questions of conception and measurement, Goodin also raises several points which fruitfully indicate areas of future work, and which I want to note here, if only briefly. First, there is the matter of distinguishing and evaluating the various policy levers a society might engage to realize a just distribution of free time. These include, as Goodin notes, beyond more generally equalizing resources, reducing and redistributing necessary time (Goodin 2017: 37-38, 42-43). In addition, a society can realize a just distribution of time by ensuring that citizens have access to free time (e.g. counteracting overemployment, see Rose 2016: 60, 78-81, 138-40), and entitling citizens to a greater portion of a society's aggregate available free time, even if at the cost of lower rates of economic growth (Rose 2016: 128-34). Taken together, these means provide substantial scope to affect the amount and distribution of a society's free time. Second, there is the question of what conditions enable citizens to make effective use of their free time - which I take up next in engagement 
Justice and the Resource of Time: a Reply to Goodin, Terlazzo, von Platz, Stanczyk, and Lim

with Terlazzo's argument. And, finally, there is the question of how arguments for a claim to free time interact with those for a claim to various valuable goods in work. While the former might undermine the latter (if arguments for valuable work depend on how people must spend most of their time working), the arguments might instead apply in tandem, such that people have claims to these goods - as Goodin suggests - within and outside of work. ${ }^{2}$

\section{THE SOCIAL CONDITIONS FOR THE EFFECTIVE USE OF FREE TIME: A RESPONSE TO TERLAZZO}

Terlazzo generously proposes that the argumentative framework I use to establish citizens' legitimate claims to free time may serve as a model to argue for citizens' claims to other under-explored resources. She takes up this project by instructively arguing that, on the basis of the effective freedoms principle - which ensures that citizens possess the means that are generally required to make effective use of their formal liberties and opportunities - citizens have a claim to a distinctive internal resource: a sense of moral entitlement to make use of their basic liberties.

Terlazzo's example of Irma illustrates how a lack of a sense of moral entitlement may compromise one's ability to effectively exercise one's freedoms. Irma is an affluent housewife who has ample money and free time, but she believes that a woman's place is in the family, and that she is morally obligated to devote all of her time to taking care of her home and children. While Irma is aware of her formally-guaranteed freedoms and has the temporal and material resources to exercise them, she does not feel morally entitled to do so. As such, Irma does not participate in politics or community life, or engage in any other pursuit beyond caring for her family (Terlazzo 2017: 93-94).

Terlazzo develops several alternative ways to specify this resource, but to take one version, we can understand it, analogous to Rawls's primary good of the social bases of self-respect, as a claim to the social conditions that reliably foster the belief that one is morally entitled to exercise one's basic liberties. Terlazzo argues that the social conditions that would ground this belief would likely be some standard of formal education and broad exposure to people living diverse lives (Terlazzo 2017: 101-102). If

2 See, for instance, Gheaus and Herzog (2016: 80) for the suggestion that if people had far more free time, there would be less, if any, reason to be concerned with the distribution of people's ability to realize these goods within their paid work. For a discussion of these argumentative possibilities, see Hsieh (2008: 76-79), and for arguments that might apply within and outside of work, see, for instance, Muirhead (2004) and Arnold (2012). 
Irma was not educated to consider or exposed to alternative views about the proper role of women in the family and in society, and therefore she has always held, and is not open to revising, her beliefs about women's domestic obligations, she would then lack the relevant resource. ${ }^{3}$

Terlazzo takes up the argument for the resource of free time to argue, in parallel, for the resource of moral entitlement. In response, I will, in turn, take up her argument to show how a claim to this type of internal resource interacts with citizens' claims to free time.

The effective freedoms principle grounds citizens' claims to a set of resources. By extension, on the same grounds, citizens also have claims to the social conditions that are generally required to make effective use of these resources for the exercise their liberties. As such, citizens have claims to fair shares of free time, and to the social conditions that allow them to make effective use of their free time to exercise their liberties (Rose 2016: 90, 142).

To see how citizens might possess free time under conditions that undermine their effective use of it, and in turn the effective exercise of their liberties and opportunities, consider the following cases. Ann has a fair amount of free time, but she is a retail employee who must work evenings and weekends, so she only has free time during weekdays when her family and friends, as well as most other people, are working. Beth is a live-in housekeeper and nanny and, though she too has a fair amount of free time, she only has free time in brief windows between meeting the responsibilities of her position. Chris works in a distribution center, and though he also has enough free time, it does not occur on a predictable schedule because he is regularly required to work overtime without advance notice; similarly for David, a restaurant server, with an on-call shift schedule (or zero-hours contract). Though Ann, Beth, Chris, and David all have a fair amount of free time, due to the constraints imposed by the terms of their employment, they do not have this time under conditions that allow them to effectively use it to exercise their liberties (Rose 2016: 142-143).

To address these sorts of constraints on the effective use of one's free time, I argue that, in addition to having a fair amount of free time, citizens must enjoy their shares of free time under a set of fair conditions. In particular, first, one must have access to sufficient periods of shared free time; and second, one must either have discretion over when one's free time occurs, or, if one has limited discretion, one's free time must occur in generally usable periods and on a predictable schedule (Rose 2016: 143-44).

3 For a related argument, see Ferracioli and Terlazzo (2014). 
The book focuses on these specifically temporal conditions that must obtain for the effective use of one's free time, but these are, of course, not the only ways one's effective use of one's free time may be constrained, nor are these the only conditions that must obtain for one to be able to effectively use one's free time to exercise one's liberties and opportunities. The effective use of one's free time also requires, for instance, various social conditions related to space. Effective freedom of association calls for access to both private and public spaces that meet a set of conditions, including, as Goodin notes, public parks that facilitate social mixing (Goodin 2017: 44; Rose 2016: 109 n. 32), as does effective exercise of the political liberties. The effective use of one's free time to more generally pursue a conception of the good also requires access to diverse opportunities in the built and natural environment, which we might think of as free time infrastructure (Rose 2016: 8; see also Weeks (2011: 167-171) on the creative potential of free time, which in turn can expand these and other opportunities).

Terlazzo provides the useful example of Irma to demonstrate how an absence of a sense of moral entitlement, like an absence of free time, can undermine the effective exercise of one's freedoms. But her example also constructively highlights how the effective use of one's free time can itself be hindered in other ways, and more broadly, how ensuring that citizens can make effective use of their formal freedoms requires an interlocking set of resources and social conditions. To illustrate how citizens' claims are connected, consider education. On the basis of the effective freedoms principle, citizens are entitled to a system of education that fosters their all-purpose internal capacities, including, following Terlazzo's argument, a sense of moral entitlement. In turn, such an education system serves as one of the social conditions that enables citizens to make effective use of their free time to exercise their liberties. Bertrand Russell, for instance, who argued that 'four hours' work a day should entitle a man to the necessities and elementary comforts of life, and that the rest of his time should be his to use as he might see fit", was quick to add that education would be "an essential part of any such social system" in order to ensure that people were equipped to make use of their free time (Russell 2004: $12)^{4}$

4 This aim might inform both schools' curricula (e.g. civics education) and schedules (e.g. recess, school vacations), so that students have both preparation for and experience with the effective use of free time. I thank Tom Parr for suggesting this point. Children might also have a claim to free time to realize non-instrumental goods; for an argument that children have claims to free time, and to the means to make effective use of that time (e.g. playgrounds, extra-curricular opportunities), to realize distinctive childhood goods, see Neufeld (2018); see also Gheaus (2015); Rose (2016: 63 n. 29). 
It is essential - especially as we consider the prospect of citizens having far greater amounts of free time - to remember that the effective freedoms principle grounds citizens' claims not only to a fair amount of free time, but, as Terlazzo's argument highlights, to the social conditions that allow them to make effective use of it to exercise their liberties and opportunities. Citizens must enjoy their free time under social conditions that allow for its value to be realized.

\section{THE SCOPE OF THE EFFECTIVE FREEDOMS PRINCIPLE: A RESPONSE TO VON PLATZ}

The argument that the effective freedoms principle grounds a claim of all citizens to free time can be understood, von Platz argues, in two ways, corresponding to two readings of the principle. Von Platz contends that, while both arguments are sound and establish that free time is a proper subject of justice, neither establishes an additional way in which citizens are entitled to free time (von Platz 2017: 60). The two ways that von Platz argues the effective freedoms principle can be interpreted are: first, the basic liberties reading, on which citizens have a claim to an adequate amount of the resources required to exercise their basic liberties; and second, the general liberty reading, on which citizens have a claim to a fair share of the resources required to pursue their conceptions of the good, with "fair" meaning only that all should receive their due (von Platz 2017: 52).

Von Platz argues that, while the first reading yields a claim to only sufficient free time to exercise one's basic liberties, the fair distribution of free time among cooperating citizens remains an issue of justice beyond the point at which all have enough time to exercise their basic liberties. Yet, turning to the second reading, von Platz contends that it cannot support this stronger claim to a fair share (von Platz 2017: 54-56). In response, von Platz suggests a way to extend the book's argument to establish that citizens have a claim of distributive justice to a cooperatively fair share of free time (von Platz 2017: 57-59).

I take von Platz's argument on behalf of a claim to free time, as a distributive claim to the benefits of cooperation, to be compatible with my own, and would instead characterize his argument as one way of specifying the effective freedoms principle, rather than as an extension that is necessarily "outside the scope" of the principle (von Platz 2017: 57).

The effective freedoms principle allows for more variation and is incorporated into different theories of distributive justice in a wider range of ways than von Platz's description may indicate. As I argue, there is 
considerable diversity in the form the principle takes within different liberal egalitarian theories, from what grounds citizens' claims and the conditions under which their claims are fair, to which liberties and opportunities its scope extends, as well as the currency of citizens' shares and which distributive principles apply to their shares. Additionally, some theories recognize the principle directly, while others realize it indirectly through other principles (Rose 2016: 69-73, 85-89). ${ }^{5}$ The principle is, by construction, stated broadly - as a "legitimate claim to a fair share of the resources that are generally required to exercise their formal liberties and opportunities" - to encompass this diversity. Across these variations, the principle's core is the commitment, central to liberal egalitarian theories of social justice, to ensuring that citizens possess the means to exercise their freedoms (Rose 2016: 6-7).

One version of the effective freedoms principle is von Platz's basic liberties reading, grounding a sufficientarian claim to the resources that are generally required to exercise one's basic liberties. Yet, the principle is also developed in a variety of other ways, and these alternatives can be seen as different ways of specifying von Platz's general liberty reading of the principle.

Some versions of the effective freedoms principle, while grounding sufficientarian claims, are not limited in scope to resources for the basic liberties. Cécile Fabre's (2006: 32-33) theory of social rights, for one, holds that citizens have "rights to the all-purpose resources they need in order to lead" a life in which they can frame, revise, and pursue a conception of the good with which they identify. ${ }^{6}$ Elizabeth Anderson's (1999: 315-21; 2001: 70-71) theory of democratic equality, to take another, holds that citizens are entitled to the social conditions, including the resources, necessary to have effective access to levels of functioning sufficient to stand as equals in

5 The two principles of John Rawls's theory of justice as fairness provide an example of how a theory may realize the effective freedoms principle indirectly through other principles. In addressing the question of how to ensure that citizens' liberties are not merely formal, Rawls argues that, while the first principle requires guaranteeing the fair value of the political liberties, it does not specifically guarantee the fair value of all the basic liberties, because to do so would be "superfluous, given the difference principle" (Rawls 2001: 148-51). The difference principle "underwrites the worth" of the guarantees of the basic liberties and fair equality of opportunity principles, and so the principles of the theory taken together ensure that citizens enjoy the worth of their formal liberties and opportunities (Rawls 2005: $5-6)$.

6 See also Fabre (2000: 18-20). In a notable exception to the general neglect of temporal resources in theories of justice, Fabre cites as an example of lack of means someone "who needs to work fifteen hours a day in order to subsist", and so "will not be able to pursue his chosen conception of the good, precisely for lack of time and money; in fact he most probably will not able, for these very same reasons, to pursue any conception of the good which does not involve working fifteen hours a day" (Fabre 2006: 31). 
a democratic state and civil society, and as equal participants in a system of cooperative production.

Other versions of the effective freedoms principle yield, as von Platz favors, stronger claims of distributive equality grounded in cooperative fairness. Stuart White's (2003: 26, and 25-76) account of justice as fair reciprocity, for instance, which is founded on a commitment to substantive economic reciprocity, holds that citizens have presumptively equal rights to the satisfaction of their opportunity interests, including their "interests in access to the resources necessary for pursuing the ideals that animate their personal lives".

As such, the effective freedoms principle's central commitment - to ensuring that citizens possess the means to make effective use of their freedoms - can be specified in a range of ways. Citizens' "legitimate claims to a fair share" can, as von Platz advocates, be grounded in the cooperative norms of fairness of distributive justice, and if the principle is specified in this way, it can yield claims to a cooperatively fair share of free time. The book aims to show that any theory that holds that citizens have claims to the resources required to exercise their freedoms - as all liberal egalitarian theories of social justice do - must recognize that citizens have claims to free time. From this recognition, citizens' claims to free time ought, then, to be incorporated into different theories of justice, in various ways and with varying implications, depending on different theories' particular principles - with von Platz's proposal being one welcome way of specifying citizens' claims to free time.

\section{CONFRONTING THE CLASS DIVIDE: A RESPONSE TO STANCZYK}

Stanczyk takes up the question of how we ought to regard the claims to free time of wealthy professionals. Stanczyk makes two arguments: First, though affluent professionals may loudly lament how little free time they have, they ought to be regarded, by virtue of their wealth and occupational opportunities, as already having (more than) their fair shares of free time. As such, wealthy professionals have no claim of justice to work hours protections (e.g. protections that entitle one to work no more than a maximum number of hours; to have predictable schedules; to have short or flexible schedules or leave time for caregiving; or to not have to work during a common period of free time) (Stanczyk 2017: 67-71). Second, to extend such work hours protections universally, including to wealthy professionals, would not only be unjustified, it would conflict with the aim of securing a just distribution of free time, and distributive justice more 
Justice and the Resource of Time: a Reply to Goodin, Terlazzo, von Platz, Stanczyk, and Lim

broadly (Stanczyk 2017: 67, 71-73).

This is an important and complex question, and one that goes, as Stanczyk rightly argues, to the question of how liberal egalitarians ought to confront the class divide. I will take up Stanczyk's two arguments in turn.

The first argument - that wealthy professionals ought to be regarded as already having their fair shares of free time - is part of the larger question of how choices for which one might be held responsible ought to affect the assessment of one's free time (Rose 2016: 60-65). Say a corporate lawyer has inherited, or has accumulated after enough years in her highly-paid position, a substantial amount of wealth, such that, if she were to quit her position, the terms of which require her to work long hours, she could use this wealth to meet her basic needs without ever working another day. Or, say that a psychiatrist, who hasn't inherited or accumulated wealth but earns a generous income working short and flexible hours, leaves her practice to work as an interior designer, and now must work long and antisocial hours to earn a decent income. Though the corporate lawyer and the interior designer are required to work these hours by the terms of their current employment, they would not have to if they were to take advantage of the privileges afforded by their wealth and occupational opportunities.

The book's core argument, so that it applies broadly across different theories of justice, is constructed to be open to taking different positions on these questions of responsibility-sensitivity, and so is open to holding that such affluent professionals, despite their long work hours, are properly regarded as having their fair shares of free time, and thus have no claim of justice to work hours protections.

With respect to wealth, I argue that a society may democratically decide that, if one has personal wealth above some amount, any paid work one does ought to be treated as a use of one's free time, rather than as necessary time. This threshold level might be set higher or lower, or include or exclude different asset types, depending on various circumstances (Rose 2016: 64). Stanczyk's argument also rightly presses that this threshold should not be left solely to democratic decision, and is properly constrained by principles of distributive justice, if, for instance, it were necessary to treat the work hours of those above some threshold level of wealth as discretionary in order to meet the claims to free time of the less well off.

With respect to occupational choice, the core argument is open to taking the more responsibility-sensitive position, such that if one chooses to work in an occupation that requires longer hours than another occupation one could have chosen, the assessment of how much free time 
one has would reflect one's occupational choice set, not the occupation one has in fact chosen.

While the core argument allows for taking this position, in developing the argument and its implications, I instead argue that the importance of the interest in freely choosing one's occupation provides a weighty reason to allow citizens to exercise this choice without forfeiting their claim to other important interests, including to free time. Nonetheless, while citizens do have an all things considered claim to a fair share of free time, because it may sometimes be impossible or prohibitively socially costly to guarantee this claim for particular occupations, citizens have only a pro tanto claim to free time in their chosen occupational position (Rose 2016: $90-92)$. This pro tanto claim can be defeated by several types of reasons, including, as Stanczyk's argument again presses, if guaranteeing free time to privileged professionals in their chosen occupations would unavoidably conflict with meeting the claims of those who have less advantageous occupational opportunities.

As such, even if citizens do have a pro tanto claim to free time in their chosen occupational positions, if extending work hours protections to all, including the most privileged, would necessarily conflict with realizing the claims to free time of the less privileged, my argument is open, and indeed would favor, regarding the long work hours of those privileged by wealth and occupational opportunities as discretionary uses of their free time. Time-pressed wealthy professionals who have access, by virtue of their wealth or occupational opportunities, to free time would - if there is such a conflict - then have no claim of justice to work hours protections.

Yet, to turn to Stanczyk's second argument, we should not be too quick to assume that this conflict would necessarily arise. Stanczyk argues that the conflict arises because providing work hours protections universally would be economically regressive: some of the affluent professionals would inevitably choose to work less, resulting in lower profits and salary incomes, and thus a smaller tax base, diminishing the government revenue available to meet the claims of the less well off (Stanczyk 2017: 71-72).

To start, it might be the case that, for empirical reasons, universal work hours protections would in fact better realize the claims of the less well off. Stanczyk grants that there may be other reasons to implement work hour protections universally, such as economic efficiency or political strategy (and, we could add, gender equality) (Stanczyk 2017: 68). But, we might also raise questions about the assumed economic regressivity. To pose two other possible dynamics, it might be the case that harried professionals, with their long and always-on work hours, would in fact be, in total, more productive, and would be productive in ways that are more creative and 
Justice and the Resource of Time: a Reply to Goodin, Terlazzo, von Platz, Stanczyk, and Lim

socially beneficially, if they had shorter and more flexible work schedules (Rose 2016: 130-31). Or, the fact that the those with high social status work long hours might promote social norms valorizing this culture - with "busyness as the badge of honor for the new superordinate working class," as sociologist Jonathan Gershuny puts it - with the effect that these norms undermine the ability of workers across society to choose not to work long hours (2005; see also 2009; Rose 2016: 138-39).

Further, whether extending work hours protections universally would conflict with the aim of securing a just distribution of free time, or distributive justice more broadly, depends on the requirements and possibilities of the underlying theory of justice. On a theory with a sufficientarian distributive standard, for instance, there may easily be no conflict between universal work hours protections and realizing all citizens' claims to a sufficient amount of free time (and other resources). Or, on a theory with a more egalitarian distributive standard, there might similarly be no conflict between extending work hours protections universally and realizing distributive justice more broadly, given that there would be a far less unequal distribution of wealth and occupational opportunities than in the society, resembling our own today, that Stanczyk describes.

To draw these points together, first, the core argument is straightforwardly open, if maximally responsibility-sensitive, to holding that the long work hours of wealthy professionals are discretionary uses of their free time. Moreover, even if citizens have pro tanto claims to free time in their chosen occupational positions, wealthy professionals have no claim of justice to work hours protections if their universal extension would necessarily conflict with realizing the claims to free time of the less well off. But, second, whether the presumptive claim to universal work hours protections is defeated depends on whether this conflict does in fact arise, and unavoidably so - a question that cannot be answered without looking further at both the potential empirical dynamics and the underlying theory's requirements and possibilities.

\section{A REPUBLICAN SOCIAL JUSTICE ARGUMENT FOR FREE TIME: A RESPONSE TO LIM}

Lim persuasively develops a republican case for an entitlement to free time, with a carefully constructed two-stage argument. First, republican non-domination requires robust checking mechanisms to ensure that power-holders are forced to track the interests of their power-subjects. In 
the domain of the workplace, for instance, employees must have mechanisms to check employers' power, through both contestation (e.g. political organizations and unions to dispute decisions) and justification (e.g. workplace committees and employee representation on boards to participate in decisions). Importantly, establishing, maintaining, and participating in these checking mechanisms - and citizens' checks on political power more generally - takes time. Thus, Lim argues, the protection of republican non-domination entitles citizens to sufficient time for political engagement (Lim 2017: 81-86).

Second, Lim argues that providing citizens with time specifically for political engagement, either compulsorily or conditionally, would be contrary to republican commitments. For the state to ensure that citizens devote this allotted time to political engagement would require invasions of privacy, extensive surveillance, coercive enforcement, and state judgment about what activities are worthy, and would also likely be contrary to the cultivation of genuine civic virtue. To avoid these pitfalls, citizens' claims to time for political engagement ought to be provided instead in the form of free time, for citizens to devote to any activities of their choosing (Lim 2017: 86-89).

Lim argues that, unlike liberal egalitarians who can make a "straightforward" case for free time, this republican argument is an "instrumental" one ( $\operatorname{Lim}$ 2017: 75). While Lim is right to argue that this republican justification for free time is less straightforward, it is perhaps worth clarifying that, on both accounts, citizens' claims to free time are grounded in its instrumental value as a resource. To characterize the contrast, we might instead say that this republican argument is both more indirect (citizens' claims to free time run through their claims to political time) and contingent (citizens' claims to free time depend on the nonviability of claims to specifically political time).

In examining the "temporal dimension within republicanism", Lim aims to see how republicanism might ground an entitlement to free time, and she readily notes that the argument she develops is not necessarily the only republican path available (Lim 2017: 75). In the spirit of her argument, in response I will sketch another possible republican route to an entitlement to free time. To do so, I will take up Lim's suggestion to look toward the connection between free time and social equality.

To be free citizens, Philip Pettit argues, republican citizens must enjoy freedom as non-domination not only in their relations to the state, with checks against public domination, but also in their social relations with one another, with blocks against private domination. To protect citizens against private domination, the republican theory of social justice requires 
"a level of protection and resourcing for people's basic liberties - a level of entrenchment-that would enable them to count as equals in the enjoyment of freedom" (Pettit 2014: 82). This ideal of equal status is grounded in the image of the liber, or free citizen, from the republican tradition, and requires that citizens can pass "the eyeball test": they can "look one another in the eye without reason for fear or deference" (Pettit 2014: 82). Free citizens can "walk tall and assume the public status...of being equal in this regard with the best," and "do not depend on anyone's grace or favour for being able to choose their mode of life" (Pettit 2012: 84, 82). The republican theory of social justice, then, requires that, to enable citizens to meet the eyeball test, all citizens must enjoy a threshold level of resources and protections for the exercise of their basic liberties (yielding, as such, a sufficientarian version of the effective freedoms principle) (Pettit 2012: 85, and 75-129; 2014: 99, and 77-108; Rose 2016: 70n8).

From these grounds, it is then possible to argue that republicans ought to be concerned with the distribution of free time, insofar as inadequacies in citizens' shares of the resource of free time undermine citizens' ability "to stand on an equal footing" (Pettit 2014: 80). ${ }^{7}$ To see how this might be the case, say that while some people have an abundance of free time, and devote it to social and community life, time-consuming political activities, and a wide array of educational and cultural forms of personal development, others must work very long or unsociable hours, and these time-poor citizens have scant opportunity to participate in such endeavors. It is not difficult to imagine how these deficits of free time might, like material poverty, undermine citizens' equal standing. Or, consider how if one has very little free time, or if the terms of one's employment render one always on call to work demands or exposed to unpredictable work schedules, one might be dependent on the favors and goodwill of others and thus liable to their interference. One might well have to "bow or scrape, toady or kowtow, fawn or flatter" (Pettit 2012: 82) with one's bosses and coworkers, and perhaps one's family or friends, in an attempt to manage and reconcile one's personal commitments and obligations with these onerous and intrusive work demands. Again, it is apparent how shortcomings in both in the amount and the conditions of citizens' shares of free time might

$7 \quad$ Though the eyeball test primarily requires that citizens possess an adequate level of resources and protections for the exercise of their basic liberties, it also imposes limits on how vast inequalities in resources can be, as citizens' equal status depends in part in how their resources compare with others', and if they "compare too unfavourably" that is likely to affect the "standing they can command in one another's eyes" (Pettit 2012: 90-91). It seems that the eyeball test would also impose limits on how vast inequalities in free time could unobjectionably be, but this argument primarily yields a sufficientarian claim to free time. (On the relationship between social equality and distributive claims to free time, see Rose 2016: 85-89). 
undermine their equal status as free citizens.

In this way, it is possible to construct another republican path to a claim to free time, building on the idea that republican freedom is "a freedom that presupposes the resources required to make it effective" (Pettit 2014: 103). On these grounds, one might argue, citizens are entitled to the resource of free time for the exercise of their basic liberties, to the extent that it enables them to enjoy equal status as free citizens. Such an argument, like Lim's, provides a republican connection between free time and social equality, as all citizens must possess free time on terms that enable them to pass the eyeball test.

Following Lim's lead in exploring the temporal dimensions of republicanism, there are likely other ways that republican commitments could yield a case for free time-and these further possible arguments, like the one described here, may be taken as complements to the republican argument developed by Lim.

\section{CONCLUDING COMMENT}

To have one's work read by such excellent and thoughtful contributors is an honor. I am grateful to the contributors for devoting their attention and time to engaging with the book, doing so in such a constructive spirit, and for providing so many threads about which to continue thinking. I am also grateful to the editors, in particular to Tom Parr, for his valuable comments and for bringing this symposium to fruition.

\section{BIBLIOGRAPHY}

Anderson, E., 1999: "What Is the Point of Equality?" Ethics 109: 287-337.

Anderson, E., 2001: “Optional Freedoms.” In What's Wrong with a Free Lunch?, ed. J. Cohen and J. Rogers, 70-74. Boston: Beacon Press.

Arnold, S., 2012: “The Difference Principle at Work." The Journal of Political Philosophy 20: 94-118.

Bittman, M., 2011: “Goodin et al.'s New Measure of Freedom: Authors Meet Critic.” Social Indicators Research 101: 185-87.

Fabre, C., 2000: Social Rights under the Constitution: Government and the Decent Life. Oxford: Oxford University Press.

Fabre, C., 2006: Whose Body Is It Anyway? Justice and the Integrity of the Person. Oxford: Oxford University Press.

Ferracioli, L. and R. Terlazzo, 2014: "Educating for Autonomy: Liberalism and Autonomy in the Capabilities Approach.” Ethical Theory and Moral Practice 17: 443-55. 
Gershuny, J., 2005: "Busyness as the Badge of Honor for the New Superordinate Working Class.” Social Indicators Research 72: 287-314.

Gershuny, J., 2009: "Veblen in Reverse: Evidence from the Multinational Time-Use Archive." Social Indicators Research 93: 37-46.

Gheaus, A., 2015: “The 'Intrinsic Goods of Childhood' and the Just Society." In The Nature of Children's Well-Being: Theory and Practice, edited by Colin Macleod and Alexander Bagattini, 35-52. London: Springer.

Gheaus, A. and L. Herzog, 2016: “The Goods of Work (Other Than Money!).” Journal of Social Philosophy 47: 70-89.

Goodin, R.E., 2017: “Freeing Up Time.” Law, Ethics and Philosophy 5: 37-46.

Goodin, R.E., J.M. Rice, A. Parpo, and L. Eriksson, 2008: Discretionary Time: A New Measure of Freedom. Cambridge: Cambridge University Press.

— R.E., J.M. Rice, A. Parpo, and L. Eriksson, 2011: "Discretionary Time: A Rejoinder." Social Indicators Research 101: 189-92.

Hobbes, M., W.T. de Groot, E. van der Voet, and S. Sarkhel, 2011: "Freely Disposable Time: A Time and Money Integrated Measure of Poverty and Freedom.” World Development 39: 2055-68.

Hsieh, N., 2008: "Survey Article: Justice in Production." The Journal of Political Philosophy 16: 72-100.

Lim., 2017: "Domination and the (Instrumental) Case for Free Time." Law, Ethics and Philosophy 5: 74-90.

Muirhead, R, 2004: Just Work. Cambridge: Harvard University Press.

Neufeld, B.E., 2018: “'The Kids Are Alright': Political Liberalism, Leisure Time, and Childhood." Philosophical Studies 175: 1057-70.

Pettit, P., 2012: On the People's Terms: A Republican Theory and Model of Democracy. New York: Cambridge University Press.

- 2014: Just Freedom: A Moral Compass for a Complex World. New York: W.W. Norton.

Rawls, J., 2001: Justice as Fairness: A Restatement. Cambridge, Mass: Belknap Press of Harvard University Press.

— 2005: Political Liberalism. Expanded ed. New York: Columbia University Press.

Rose, J.L., 2016: Free Time. Princeton: Princeton University Press.

Russell, B., 2004: “In Praise of Idleness.” In In Praise of Idleness, and Other Essays, 1-15. London: George Allen \& Unwin, 1935; repr. New York: Routledge.

Sen, A., 1983: “Poor, Relatively Speaking." Oxford Economic Papers, New Series, 35 (2): 153-69. Stanczyk, L., 2017: “Free Time and Economic Class.” Law, Ethics and Philosophy 5: 62-73.

Terlazzo, R., 2017: "Entitlement and the Resource of Free Time." Law, Ethics and Philosophy 5: 91-104.

von Platz, J., 2017: “Free Time, Freedom, and Fairness." Law, Ethics and Philosophy 5: 47-61.

Weeks, K., 2011: The Problem with Work: Feminism, Marxism, Antiwork Politics, and Postwork Imaginaries. Durham: Duke University Press.

White, S., 2003: The Civic Minimum: On the Rights and Obligations of Economic Citizenship. Oxford: Oxford University Press.

Williams, J.R., Y.J. Masuda, and H. Tallis., 2016: “A Measure Whose Time Has Come: Formalizing Time Poverty.” Social Indicators Research 128: 265-83. 